\title{
Effect of feed allowance at pasture on the lying behaviour of dairy cows
}

\author{
Keelin O’Driscoll ${ }^{\mathrm{a}, *}$, Eva Lewis ${ }^{\mathrm{b}}$, Emer Kennedy ${ }^{\mathrm{b}}$ \\ ${ }^{a}$ Teagasc, Pig Development Department, Animal \& Grassland Research and Innovation Centre, Moorepark, Fermoy, Co. Cork, Ireland \\ ${ }^{\mathrm{b}}$ Teagasc, Grassland Science Research Department, Animal \& Grassland Research and Innovation Centre, Moorepark, Fermoy, Co. Cork, Ireland
}

A R T I C L E I N F O

\section{Keywords:}

Pasture

Feed restriction

Lying

Dairy cow

\begin{abstract}
A B S T R A C T
In temperate climates where cows are primarily managed at pasture shortages of grass could result in nutritional deficits for the cow and may have a variety of behavioural consequences. Lying behaviour is one of the most researched aspects of dairy cow behaviour, and can provide insights into cow welfare and physiological state. This study investigated the effect of daily herbage allowance (DHA) on the lying behaviour of dairy cow during early lactation. Ninety-six cows were randomly assigned to one of eight treatments in a $2 \times 4$ factorial design; experimental duration ( 2 week $(2 \mathrm{~W})$ or 6 week $(6 \mathrm{~W})$ ), and nutritional levels (DHA) $(60 \%, 80 \%, 100 \%$ or $120 \%$ of intake capacity). Cows were assigned to treatment at $28 \pm 8.4$ days in milk, and lying behaviour of cows in the $6 \mathrm{~W}$ treatments recorded using modified voltage data loggers on 4 occasions; the week prior to the start of the experiment, during week 3 (MID), and week 6 (LATE), and 7 weeks after the study concluded (POST), when the cows were all returned to a feed allowance of $100 \%$ intake capacity. Although there was an effect of treatment on daily lying time $(\mathrm{P}<0.01)$, with the $60 \%$ cows spending less time lying than the $120 \%(\mathrm{P}<0.01)$, cows in all treatments spent at least $9 \mathrm{~h}$ lying per day throughout the experiment. Daily lying time increased as the grazing season progressed $(\mathrm{P}<0.001)$. Feed allowance affected both lying bout duration $(\mathrm{P}<0.01)$ and number $(\mathrm{P}<0.05)$, with cows on the highest feed allowance having the highest values for both. There was an effect of feed allowance on the time that cows first lay down after both morning and afternoon milking $(\mathrm{P}<0.001)$, with a similar pattern for both times; the lower the feed allowance, the longer it took. During the POST period, this pattern was no longer evident in the afternoon, but still present in the morning. None of the treatments imposed resulted in daily lying times lower than those reported in other studies at pasture. However, the significant differences in patterns of lying during the day could be reflective of satiety level; the patterns of lying in cows with a low feed allowance compared to those with an allowance aligned with intake capacity are in agreement with previous research. Herd level recording of lying behaviour, relative to time since milking and/or fresh feed allocation, has potential for use as an animal welfare indicator for cows at pasture.
\end{abstract}

\section{Introduction}

In Ireland, where seasonal pasture based systems predominate, dairy cows are primarily fed by allowing them to graze herbage directly so that feed costs remain low (Finneran et al., 2010). However, herbage growth can be low or extremely variable until late spring, with supply dependant on the prevailing climatic conditions of a given year (Hurtado-Uria et al., 2013). Thus, in times of inclement weather, dependence on herbage during the spring in intensive grazing systems could result in the amount of available feed falling below the nutritional requirements of the cow (Ganche et al., 2013).

An animals' attempt to cope with either internal or external challenges is often initially expressed as a change to behaviour (Wechsler, 1995). Thus, observations of animal behaviour can be used to provide an indirect indication of the physiological and psychological state of the animal. Lying behaviour in dairy cows has been extensively studied, normally in relation to welfare. This is because lying is a high priority behaviour for cows, sometimes even more so than feeding behaviour (Munksgaard et al., 2005), and lying times are considered a key animal based indicator of cow comfort (Vasseur et al., 2012). Moreover, preventing cows from lying down results in behavioural and physiological responses indicative of physiological stress (e.g. increased idling, leaning, and baseline ACTH levels, Munksgaard and Simonsen, 1996; increased basal plasma cortisol concentrations, reduced pituitary responsiveness to $\mathrm{CRH}$ and increased plasma cortisol/ACTH ratio following CRH challenge, Fisher et al., 2002). Thus analysis of lying behaviour is useful in assessing their ability to cope with a particular environment or management strategy (Schütz et al., 2013).

\footnotetext{
* Corresponding author.

E-mail address: keelin.odriscoll@teagasc.ie (K. O’Driscoll).
} 
The lying behaviour of pasture based dairy cows at a range of daily herbage allowances (DHA) has previously been studied in Irish dairy production systems. In both mid to late lactation, and in early lactation, a range of DHA's did not affect total daily lying time (O'Driscoll et al., 2010a, 2015). However, the pattern of lying behaviour within a $24 \mathrm{~h}$ period was affected by DHA in both studies. In general, a high DHA is associated with a shorter standing bout immediately after milking, regardless of the stage of lactation. This is likely because of shorter grazing bouts at this time in cows with a high DHA, as feed is readily available and can be consumed quickly (O'Driscoll et al., 2010b). Moreover, in early lactation, a higher DHA was associated with shorter, and a low DHA associated with fewer, lying bouts (O'Driscoll et al., 2015). Thus, even in the absence of an effect on total daily lying time, there is clear evidence that cows adjust their patterns of lying behaviour in response to herbage allowance.

Cows naturally enter a period of negative energy balance and lose body condition in early lactation, but a low feed allowance can exacerbate this (Meikle et al., 2014). There is evidence that lying times can be related to body condition score (BCS), with a higher BCS associated with longer lying times (Matthews et al., 2012; Westin et al., 2016). Thus, besides any acute effects on lying behaviour which occur as an immediate response to a low feed allowance, a period of nutritional deficit which is long enough to have an effect on BCS could have additional effects. Cows with a low BCS spend more time grazing (Matthews et al., 2012), which reduces the available time for lying. Thus, even after a period of nutritional deprivation is over and adequate feed is once again available, there may still be effects on the daily pattern of lying behaviour for the cow.

We expected that cows provided with a range of DHAs would have similar daily lying times, but that the pattern of lying during a $24 \mathrm{~h}$ period would differ. Specifically, we hypothesised that cows on a low DHA would have an increased latency to lie after milking, and spend more time lying per hour during the night and early morning after their allowance was consumed. This would drive a shift towards longer, but fewer, lying bouts as feed allowance decreased. We also expected that these differences would increase as time on treatment increased, yet once the experimental treatment period was over and all cows were returned to the same feed allowance, the pattern of lying time across cows allocated to each treatment would converge.

\section{Materials and methods}

The study animals were located at the 'Moorepark' research farm, part of the Teagasc Animal \& Grassland Research and Innovation Centre, Moorepark, Fermoy, Co. Cork, Ireland. Measures were taken between March and May 2015. Prior to the start of the study ethical approval was attained from the Teagasc Animal Ethics Committee (TAEC69/2014). In addition, all animal procedures performed in this study were conducted under experimental licence (AE19132/P017) from the Health Products Regulatory Authority in accordance with the European Union (Protection of Animals Used for Scientific Purposes) Regulations 2012 (S.I. No. 543 of 2012).

\subsection{Animals and management}

Ninety-six dairy cows (Bos taurus; 24 primiparous and 72 multiparous) were blocked according to breed (Holstein-Friesian, $n=43$; Jersey $\times$ Friesian, $n=34$; Norwegian Red, $n=8$; Normandie $=n=1$, Mountbeliarde, $\mathrm{n}=1$ and $3 \times$ cross, $\mathrm{n}=8)$, parity $(2.64 \pm 1.50$, mean \pm SD), calving date (February 9, 2015, $\pm 8.4 \mathrm{~d}$ ), and BCS $(3.17 \pm 0.17)$ into 12 groups of 8 animals. Body condition was scored on a scale of 1 (emaciated) to 5 (extremely fat) with increments of 0.25 (Edmonson et al., 1989). Mean milk yield the week before the trial was $25.2 \pm 3.88 \mathrm{~kg} /$ day $/$ cow. Each animal within each group was randomly assigned to one of 8 treatments, in a two by four factorial arrangement. The first factor contained two levels: 2 week $(2 \mathrm{~W})$ or 6 week $(6 \mathrm{~W})$ duration. The second factor contained four nutritional levels (DHA): $60 \%, 80 \%, 100 \%$ and $120 \%$ of intake capacity. For the purposes of this study, only the $6 \mathrm{~W}$ cows were used, and all reference to experimental animals in the remainder of the manuscript refer to these animals.

After calving, cows grazed pasture by day and were housed in cubicles by night until two weeks before the start of the experiment when they were turned out to pasture full time. During the period of partial turnout cows were offered $7 \mathrm{~kg}$ DM grazed grass and ad-libitum grass silage. In addition cows received a maximum of $5 \mathrm{~kg} / \mathrm{cow} / \mathrm{d}$ of concentrates until one week before the experiment started. Concentrate supplementation was gradually reduced up to this date, after which cows were offered a grass only diet. Paddocks were dusted with calcined magnesite to prevent grass tetany. The total average intake of concentrates, pre-experiment, was $81 \mathrm{~kg} /$ cow. All cows were milked twice daily, at 0700 and 1530 . They were gathered as a single herd for milking, and returned to the paddocks at approximately 09:15 in the morning and 16:45 in the afternoon.

\subsection{Pasture and grazing management}

The experimental area was a permanent grassland site consisting of a predominantly perennial ryegrass sward (Lolium perenne L.). The swards were on average 3 years old, and no clover was present in the swards. During the treatment period, cows within each nutritional level treatment grazed as a single herd (i.e. 12 cows per herd) All herds grazed individually but in paddocks located adjacent to one another, separated by electric fences. This was to ensure similar quality pasture was offered to all treatments. At the end of the treatment period, all cows grazed as a single herd.

As pre-grazing herbage mass offered to treatments was similar, the daily area allocation in each experimental paddock was adjusted to ensure the correct pasture allowance was offered; the daily herbage allowance was calculated as a product of the area grazed per day and the pre-grazing herbage mass, calculated above $3.5 \mathrm{~cm}$. The farthest paddock was $0.8 \mathrm{~km}$ from the milking parlour. Grazing management was based on a rotational grazing system; all groups were allocated fresh grass twice daily. The use of break fences allowed a fresh allocation of pasture to be offered following each morning and afternoon milking.

\subsection{Dietary treatments}

The experimental period commenced on 9 March and dietary treatments were imposed for 42 days until 19 April. Intake capacity was calculated using the equation of Faverdin et al. (2011) and was dependent on BW, potential milk yield, BCS, week of lactation, week of gestation and age. This intake capacity figure was used as the DHA for the $100 \%$ treatment. The other DHA treatments were calculated based on the $100 \%$ DHA (i.e. $60 \%, 80 \%$ and $120 \%$ of the $100 \%$ DHA). The DHA increased as stage of lactation progressed, in line with increasing intake capacity.

Pre-grazing herbage mass was determined (above $3.5 \mathrm{~cm}$ ) by cutting two strips per treatment $(1.2 \mathrm{~m} \times 10 \mathrm{~m})$ twice weekly. Strips were cut with a motor Agria (Etesia UK Ltd., Warwick, UK), 10 grass height measurements were recorded before and after harvesting on each cut strip using a folding pasture plate meter with a steel plate (diameter $355 \mathrm{~mm}$ and $3.2 \mathrm{~kg} / \mathrm{m}^{2}$; Jenquip, Fielding, New Zealand). All mown herbage from each strip was collected, weighed and sub-sampled. A herbage sample of $100 \mathrm{~g}$ fresh weight was dried for $16 \mathrm{~h}$ at $90^{\circ} \mathrm{C}$ for DM determination. The pre-grazing herbage mass was calculated using the following equation:

[(herbage strip freshweight $\times$ DM\%) / (strip length $\mathrm{x}$ strip width)] $\times$ 10,000 
After the treatment period expired all the cows were managed at the $100 \%$ DHA. Herbage removed was used as an estimate of dry matter intake (DMI) and was calculated using the following equation:

$(($ DHA $\div$ (pre-grazing height -3.5$)) \times(3.5$ - post-grazing height $))+$ DHA

As pre-grazing herbage mass was calculated above $3.5 \mathrm{~cm}$ cows were assigned their DHA from $3.5 \mathrm{~cm}$. However, the $60 \%$ and $80 \%$ treatments had the opportunity to graze below $3.5 \mathrm{~cm}$ to increase their DMI.

\subsection{Lying behaviour}

Lying behaviour was recorded during four 'sessions'; 1 prior to (PRE), 2 during (MID and LATE), and 1 after (POST) the experimental period. The PRE session occurred over 3 days, 4-6 days prior to the treatments being imposed. During MID, cows had behaviour recorded on five consecutive days during week 3 , and LATE consisted of 5 days of behaviour recording during week 6 . The POST session took place over 5 days approx. 7 weeks after the treatments concluded, and the cows returned back to an allowance of $100 \%$ intake capacity.

Dataloggers that have been validated to record standing and lying behaviour at pasture (Tinytag Plus, Re-Ed volt, Gemini Dataloggers (UK) Ltd., Chichester, UK) were fitted and secured using a Vetwrap ${ }^{\mathrm{TM}}$ bandage to the hind leg of each cow (O'Driscoll et al., 2008). The dataloggers were attached below the hock during morning or afternoon milking the day before recording was programmed to start. They were set to record whether the cow was standing or lying at $30 \mathrm{~s}$ intervals, from midnight on first day of recording during each session. Data were filtered using a windows based programme (Tinytag ${ }^{\circledR}$ Explorer, Gemini Dataloggers, (UK) Ltd., Chichester, UK) and adjusted prior to statistical analysis as described by O'Driscoll et al. (2008). The dataloggers were placed on the legs the day prior to, and removed the day after the days used in analysis.

\subsection{Statistical analysis}

Statistical analyses for the animal based measures were carried out using SAS V9.3 (2002; SAS Institute Inc., Cary, NC). All data were examined for skew, kurtosis, and outliers before analysis by examination of box and normal distribution plots, and data were transformed where necessary.

\subsubsection{Herbage measurements}

All herbage measurements were analysed with feed allowance and week included as the main effects.

\subsubsection{Lying behaviour}

The following aspects of lying behaviour were analysed: total daily lying time, lying bout duration, number of lying bouts per day, time to first lie after morning milking, and time to first lie after afternoon milking. The Mixed procedure was used for analysis. The models included fixed effects of feed allowance, session (MID, LATE and POST), date within session, lactation number $(1,2,3,4$ and over), breed (Holstein-Friesian, Jersey $\times$ Friesian, and other) and logger, and interactions. Calving date and lying parameters recorded during the PRE session were included as covariates. Date of recording, nested within session, was included as a repeated effect. Specific hypotheses (e.g. the hypothesis that the responses of cows on the $60 \%$ treatment would be different to both the $100 \%$ and $120 \%$ treatments) were investigated using the contrast statement. To determine whether there was an overall effect of treatment at any session, the slice function was used.

The proportion of time spent lying per hour was also compared between treatments, using only data collected during the experimental period. The 120 stand/lie data points recorded by the dataloggers each hour were used to calculate the proportion of time each cow spent lying per hour on each recording day. These arithmetic mean proportions for each hour were averaged across all days within cow to provide 24 data points per animal, one for each hour of the day. These values were then compared across treatments using the Mixed procedure as before, with the removal of the continuous effect of day, but addition of the fixed effect of hour of the day (1-24).

In all analysis where the mixed procedure was used, residuals were examined to verify normality and homogeneity of variances. Differences in least squares means were investigated using the t-test, following Tukeys adjustment for multiple comparisons. Model-fit was determined in all analyses by choosing models with the minimum finite-sample corrected Akaike Information Criteria (AIC). Degrees of freedom were estimated using Kenwood-Rogers adjustment. Statistical differences were considered significant at $\mathrm{P} \leq 0.05$. Tendencies towards significance $(0.05 \leq \mathrm{P} \leq 0.10)$ are also presented. Data are presented as LSmeans \pm s.e. When transformed data were analysed, LSmeans were calculated using raw data to ease clarity of interpretation.

\section{Results}

Details of the actual herbage allowances for cows on all treatments are provided in Table 1 . There was no difference in pre-grazing height or pre-grazing DM yield $>3.5 \mathrm{~cm}$ between any of the treatments during MID $(9.1 \mathrm{~cm}$ and $1833 \mathrm{~kg} \mathrm{DM} /$ ha, respectively) or LATE $(9.6 \mathrm{~cm}$ and $1655 \mathrm{~kg} \mathrm{DM} / \mathrm{ha}$, respectively). As designed, pasture allowance was lowest for the $60 \%$ treatment and highest for the $120 \%$ treatment

Table 1

Herbage measurements recorded when cows were offered one of four feed allowance treatments: $(60 \%, 80 \%, 100 \%$ and $120 \%$ of intake capacity) for a 6 week period. MID refers to measurements taken during Week 3, and LATE during week 6 of the experiment.

\begin{tabular}{|c|c|c|c|c|c|c|}
\hline & $60 \%$ & $80 \%$ & $100 \%$ & $120 \%$ & SE & P-value \\
\hline \multicolumn{7}{|l|}{ MID } \\
\hline Pre-grazing height $(\mathrm{cm})$ & 8.5 & 9.4 & 9.1 & 9.1 & 0.53 & 0.267 \\
\hline Post-grazing height $(\mathrm{cm})$ & 2.11 & 2.71 & 3.59 & 4.03 & 0.123 & 0.001 \\
\hline DM yield (kg DM/ha) & 1726 & 1964 & 1789 & 1851 & 141.3 & 0.710 \\
\hline Pasture Allowance (kg/cow/day) & 8.8 & 11.7 & 14.6 & 17.5 & 0.12 & 0.001 \\
\hline Herbage Disappearance (kg/cow/day) & $12.2^{\mathrm{a}}$ & $13.3^{\mathrm{a}, \mathrm{b}}$ & $14.5^{\mathrm{b}, \mathrm{c}}$ & $15.8^{\mathrm{c}}$ & 0.52 & 0.001 \\
\hline Area/cow/day $\left(\mathrm{m}^{2}\right)$ & 56.7 & 59.6 & 87.4 & 97.9 & 9.58 & 0.001 \\
\hline \multicolumn{7}{|l|}{ LATE } \\
\hline Pre-grazing height $(\mathrm{cm})$ & 8.8 & 9.6 & 9.9 & 10.1 & 0.53 & 0.267 \\
\hline Post-grazing height $(\mathrm{cm})$ & 2.51 & 3.10 & 4.20 & 5.29 & 0.123 & 0.001 \\
\hline DM yield (kg DM/ha) & 1564 & 1600 & 1721 & 1736 & 141.3 & 0.710 \\
\hline Pasture Allowance (kg/cow/day) & 9.6 & 12.8 & 16.2 & 19.3 & 0.12 & 0.001 \\
\hline Herbage Disappearance (kg/cow/day) & $11.6^{\mathrm{a}}$ & $13.8^{\mathrm{b}}$ & $14.4^{\mathrm{b}}$ & $13.9^{\mathrm{b}}$ & 0.52 & 0.001 \\
\hline Area/cow/day $\left(\mathrm{m}^{2}\right)$ & 76.2 & 82.8 & 95.7 & 112.5 & 9.58 & 0.001 \\
\hline
\end{tabular}


Table 2

Total daily lying duration (hours), lying bout duration (hours), and number of lying bouts of cows fed $60 \%, 80 \%, 100 \%$ or $120 \%$ of their daily intake capacity during the mid (Week 3), late (Week 6) and post (7 weeks after conclusion of the herbage allowance treaments) experimental periods. ${ }^{\mathrm{a}, \mathrm{b}}$ indicates a difference within measurements within columns, ${ }^{A, B}$ indicates a difference within measurments within rows.

\begin{tabular}{clllllll}
\hline & & $60 \%$ & $80 \%$ & $100 \%$ & $120 \%$ & s.e.m. & P-value \\
\hline Daily lying time & Mid & $8.06^{\mathrm{a}}$ & $8.47^{\mathrm{a}}$ & $8.14^{\mathrm{a}}$ & $8.62^{\mathrm{a}}$ & 0.26 & 0.37 \\
& Late & $9.23^{\mathrm{b}, \mathrm{A}}$ & $10.00^{\mathrm{b}}$ & $9.99^{\mathrm{b}}$ & $10.34^{\mathrm{b}, \mathrm{B}}$ & 0.22 & $<0.01$ \\
& Post & $9.99^{\mathrm{b}}$ & $10.28^{\mathrm{b}}$ & $9.96^{\mathrm{b}}$ & $10.17^{\mathrm{b}}$ & 0.18 & 0.49 \\
$\begin{array}{c}\text { Lying bout } \\
\text { duration }\end{array}$ & Mid & 1.113 & 1.037 & 0.987 & 1.109 & 0.062 & 0.49 \\
& & & & & & & \\
\multirow{2}{*}{$\begin{array}{c}\text { Lying bout } \\
\text { number }\end{array}$} & 0.963 & 0.998 & 1.018 & 1.189 & 0.057 & 0.01 \\
& Post & 1.061 & 1.098 & 1.007 & 1.365 & 0.062 & $<0.05$ \\
& Mid & 6.83 & 7.23 & $7.51^{\mathrm{a}, \mathrm{b}}$ & 8.10 & 0.41 & 0.20 \\
& Late & 8.07 & 8.93 & $9.15^{\mathrm{a}}$ & 9.44 & 0.43 & 0.17 \\
& Post & 7.56 & 8.88 & $7.14^{\mathrm{b}}$ & 8.19 & 0.43 & $<0.05$
\end{tabular}

$(\mathrm{P}<0.001)$.

Given that post grazing height was not restricted, cows could graze as low as possible, greater pasture allowance restriction resulted in lower post-grazing sward heights, and there was an overall effect of treatment during both MID and LATE (Table 1). During MID, herbage disappearance was similar for the 100 and $120 \%$ treatments (Table 1 , approx. $15.2 \mathrm{~kg} \mathrm{DM} /$ cow/day). Although it was higher for the $120 \%$ treatment than the $60 \%$ and $80 \%$, the $100 \%$ treatment was similar to the $80 \%$ treatment. Similarly, although disappearance was numerically greater for the $80 \%$ than $60 \%$, there was no significant difference. During LATE, herbage disappearance was similar for the 80, 100 and $120 \%$ treatments, and higher in all three of these treatments than the $60 \%$ treatment.

During POST, when all animals were grazing as a single herd, the pre-grazing height was $10.0 \pm 1.87 \mathrm{~cm}$, pre-grazing DM yield was $1680 \pm 297.0 \mathrm{~kg} \mathrm{DM} / \mathrm{ha}>3.5 \mathrm{~cm}$, pasture allowance was $16.0 \pm 0.15 \mathrm{~kg} \mathrm{DM} / \mathrm{cow} /$ day, post-grazing height was $4.0 \pm 0.53 \mathrm{~cm}$, and herbage disappearance was $14.9 \pm 1.40 \mathrm{~kg} \mathrm{DM} / \mathrm{cow} /$ day.

\subsection{Total daily lying behaviour}

There was an effect of feed allowance on time spent lying per day $(\mathrm{P}<0.01)$, although cows on all treatments spent at least $9 \mathrm{~h}$ lying per day $(60 \%=9.10 \pm 0.13 \mathrm{~h} ; 80 \%=9.58 \pm 0.14 \mathrm{~h} ; 100 \%=9.36 \pm$ $0.13 \mathrm{~h} ; 120 \%=9.71 \pm 0.14 \mathrm{~h}$ ). Cows on the $60 \%$ treatment spent less time lying than those fed at or above capacity $(\mathrm{P}<0.01)$, and cows on the $120 \%$ treatment spent more time lying than all others $(P<0.05)$. There was an effect of session, with daily lying time increasing as the grazing season progressed $(\mathrm{P}<0.001)$. In fact, during MID, cows spent less time lying $(8.32 \pm 0.14 \mathrm{~h})$ than in LATE $(9.89 \pm 0.12 \mathrm{~h}$; $\mathrm{P}<0.001)$, or POST $(10.10 \pm 0.09 \mathrm{~h}$; P $<0.001)$.

There was no interaction between feed allowance and session on daily lying times, lying bout duration, or lying bout number (Table 2). Lying time increased following the same pattern within all treatments; lying times were shorter during MID than LATE $(\mathrm{P}<0.05$ for $60 \%$, $\mathrm{P}<0.001$ for all others), and POST ( $<0.001$ ), with no difference between LATE and POST. However, when only considering the LATE session, there was an effect of treatment on total daily lying time ( $\mathrm{P}<0.01$ ), with cows on the $60 \%$ treatment spending less time lying than the $120 \%$ treatment $(\mathrm{P}<0.05)$.

Feed allowance affected the duration of lying bouts $(\mathrm{P}<0.01)$. Cows on the $120 \%$ treatment had longer lying bouts $(1.221 \pm 0.053 \mathrm{~h})$ than those on the $100 \%(1.004 \pm 0.031 \mathrm{~h} ; \mathrm{P}=0.01), \quad 80 \%$ $(1.044 \pm 0.030 \mathrm{~h} ; \mathrm{P}<0.01)$ and $60 \%(1.046 \pm 0.033 \mathrm{~h} ; \mathrm{P}<0.05)$ treatments, and longer lying bouts when contrasted with all other
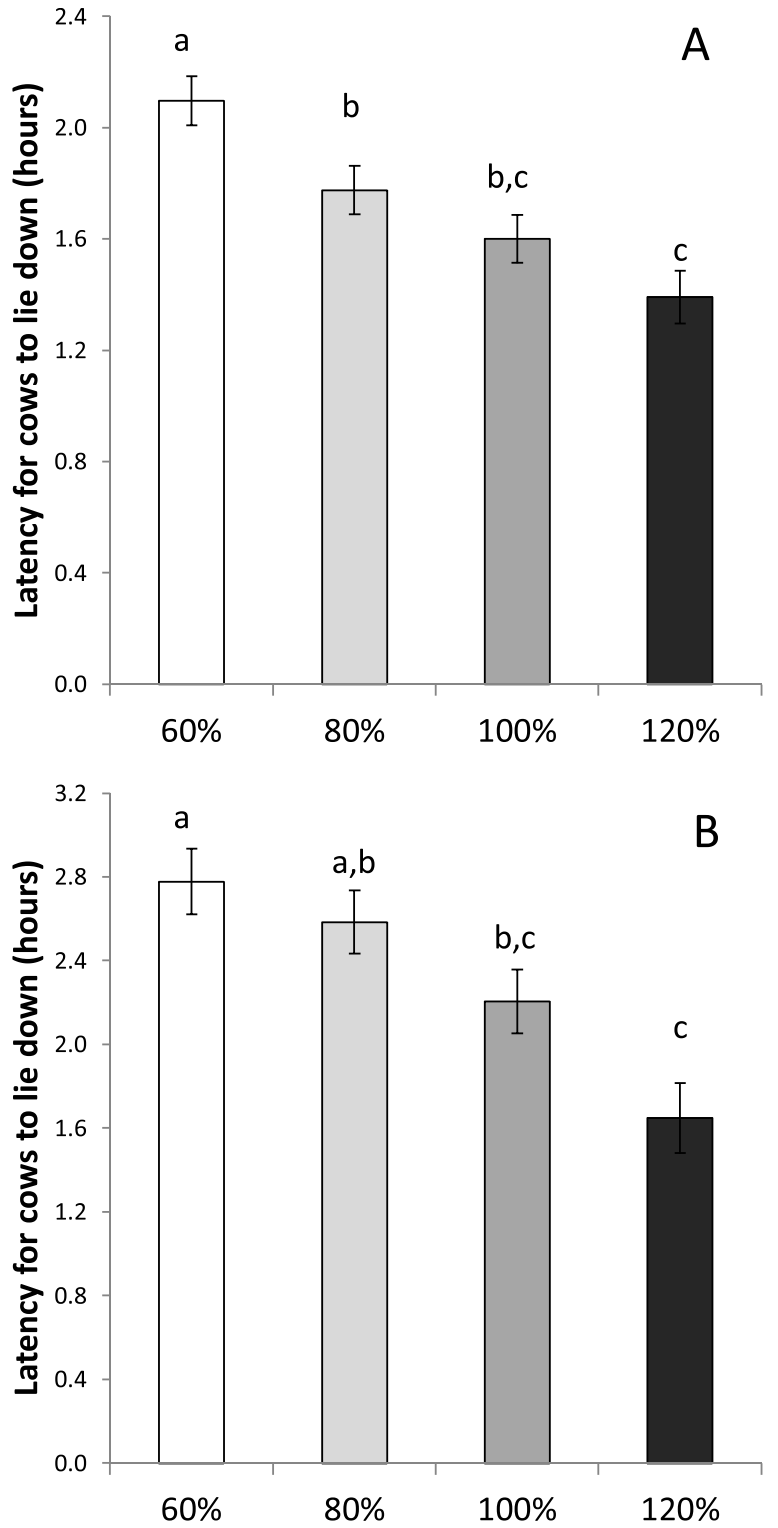

Fig. 1. Latency for cows to lie down after (A) morning milking (return to pasture approx 09:15) and (B) afternoon milking (return to pasture approx. $14: 30$ ) for cows fed $60 \%, 80 \%, 100 \%$ or $120 \%$ of their daily intake capacity.

treatments $(\mathrm{P}<0.01)$. There was no effect of recording session. However, during both LATE and POST there was an effect of treatment $(\mathrm{P}=0.01, \mathrm{P}<0.05$ respectively; Table 2$)$.

There was also an effect of feed allowance on the number of lying bouts per day ( $P<0.05$ ). Cows on the $60 \%$ treatment tended to have fewer lying bouts per day $(7.49 \pm 0.25)$ than cows on the $80 \%$ ( $8.35 \pm 0.24$ bouts/day; $\mathrm{P}=0.09$ ) and had fewer than those on the $120 \%$ ( $8.58 \pm 0.27$ bouts/day; $\mathrm{P}<0.05)$. Cows on the $100 \%$ treatment were intermediate and not different to any other treatment (7.94 \pm 0.24 bouts/day). However, cows on the $60 \%$ treatment had fewer lying bouts than cows fed at or above intake capacity (i.e. $100 \%$ and 120\%; P $<0.01$ ), and when compared with all other treatments $(\mathrm{P}<0.01)$. There was also an effect of session on lying bout number $(\mathrm{P}<0.001)$. The number of lying bouts was lowest in MID (7.42 \pm 0.18 bouts/day). Lying bout number was higher than this in LATE $(8.89 \pm 0.18$ bouts/day; $\mathrm{P}<0.001)$, which was also higher than in POST $(7.94 \pm 0.18$ bouts/day; $\mathrm{P}<0.001)$. The number of bouts only tended to be higher in POST than MID $(\mathrm{P}=0.09)$. Although there was no interaction between treatment and session, there tended to 
Table 3

The latency (hours) for cows to lie down after returning to pasture after milking in the morning (approx 09:15) and afternoon (approx. 16:45). MID refers to 3 weeks after the imposition of treatment, LATE to 6 weeks after imposition of treatment, and POST approximately 7 weeks after treatments concluded.

\begin{tabular}{lllll}
\hline & MID & LATE & POST & P-value \\
\hline Morning & $2.15 \pm 0.08^{\mathrm{a}}$ & $1.28 \pm 0.08^{\mathrm{b}}$ & $1.72 \pm 0.08^{\mathrm{c}}$ & $<0.001$ \\
Afternoon & $2.90 \pm 0.14^{\mathrm{a}}$ & $1.25 \pm 0.13^{\mathrm{b}}$ & $2.76 \pm 0.3^{\mathrm{a}}$ & $<0.001$ \\
\hline
\end{tabular}

be an effect of treatment during LATE $(\mathrm{P}=0.1)$ and there was an effect of treatment in POST $(\mathrm{P}<0.05$; Table 2$)$.

\subsection{Time to lie post milking}

There was an effect of feed allowance on the latency for cows to lie down after both morning and afternoon milking $(\mathrm{P}<0.001$ for both; Fig. 1). The pattern of behaviour was similar during both the morning and afternoon; the lower the feed allowance, the longer it took to lie down after milking. In both the morning and afternoon, cows fed below intake capacity took longer than those fed at or above to lie down ( $\mathrm{P}<0.001$ for both). Cows in the $60 \%$ treatment took longer to lie down than all other treatments combined, and cows in the $120 \%$ treatment took less time $(\mathrm{P}<0.001)$ than all others. There was also an
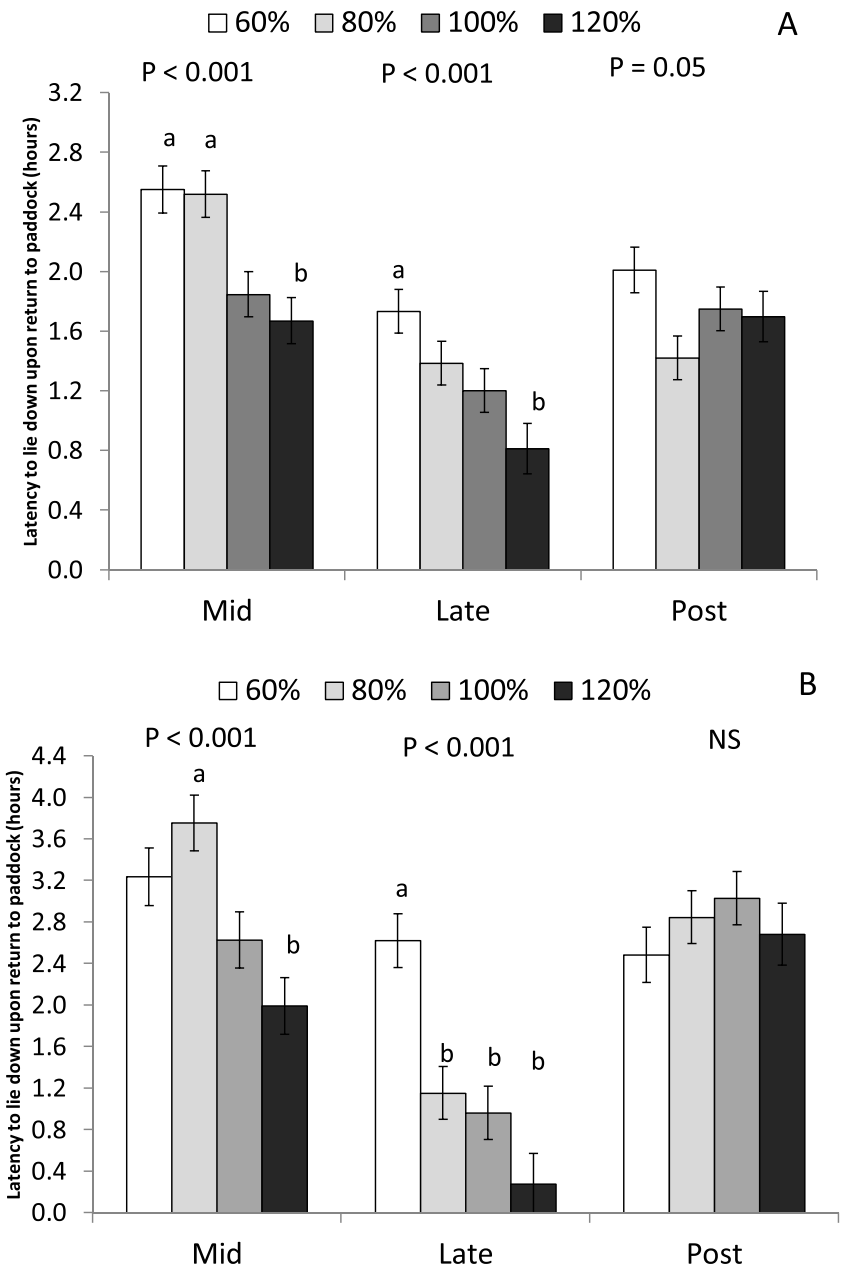

Fig. 2. The latency for cows fed $60 \%, 80 \%, 100 \%$ or $120 \%$ of their daily intake capacity to lie down after morning (A) and afternoon (B) milking during the MID, LATE, and POST experimental periods. Mid refers to 3 weeks after the imposition of treatment, LATE to 6 weeks after imposition of treatment, and POST approximately 7 weeks after treatments concluded. effect of recording session on time to lie during both morning and afternoon ( $\mathrm{P}<0.001$ for both, Table 3). Cows took less time to lie down after both morning and afternoon milking in LATE than in MID ( $\mathrm{P}<0.001$, for both). However, there was an increase again in the time to lie down after milking in both morning and afternoon by POST; in the morning, the time it took to lie was intermediate between MID and LATE $(\mathrm{P}<0.001$ for both comparisons), whereas in the afternoon the time to lie had increased to being similar to that at MID, and was significantly higher than LATE $(\mathrm{P}<0.001)$.

Finally, there was an interaction between treatment and session for both morning and afternoon time to first lie $(\mathrm{P}<0.001$ for both; Fig. 2A and B). For both morning and afternoon, during both MID and LATE, there was a strong treatment effect $(\mathrm{P}<0.001)$. The pattern was extremely similar to the overall pattern, whereby cows on the lower feed allowances took longer to lie. However, during POST, at which point all cows were provided with an allowance equalling 100\% intake capacity, this pattern was no longer present in the afternoon, and in the morning, although there was an effect of treatment $(P<0.05)$ there were no longer any pair-wise differences between treatments.

\subsection{Daily lying pattern}

There was no effect of feed allowance on the time spent lying per hour. However, there was an effect of hour of the day $(P<0.001)$, and an interaction between feed allowance and hour of the day $(\mathrm{P}<0.001$; Fig. 3). In general, the time spent lying per hour increased with feed allowance, between the hours of 09:00 and 11:00, and 16:00 and 19:00, in particular for cows in the $120 \%$ treatment. These times correspond to the hours immediately after cows were returned to the paddocks after milking.

\section{Discussion}

There are few published studies investigating nutritional factors at pasture which could affect lying behaviour of dairy cows. The main reason for this is that management either entirely or partially at pasture is generally perceived to be beneficial for cow welfare, and there are fewer hazards for behavioural problems associated with nutrition and feeding in pasture based systems, than in more confined systems (reviewed by EFSA, 2009). Indeed cows themselves show at least a partial preference for access to pasture over indoor housing (Charlton et al., 2011; Shepley et al., 2017). However, there is growing appreciation that although there are many welfare benefits to access to pasture, these benefits are not guaranteed unless management appropriately satisfies the animals' needs (Wagner et al., 2018). In addition to the potential negative consequences of variable spring weather and herbage growth in Irish seasonal dairy systems, the Irish dairy industry has experienced intensification in recent years. This has been a result of adoption of modern technologies, the abolition of EU milk quotas in 2015, and government policy, which has set a production target of a 50\% growth in milk volume by 2020 (Chen and Holden, 2018; DAFM, 2010). In pasture based systems land is the limiting resource. Thus, intensification is achieved by optimising output per hectare through increasing pasture utilization (Coffey et al., 2018), which we accomplished in the current study by increasing the stocking density of the cows. According to EFSA (2009) 'when stocking rate is too high and new pasture is not made available at regular intervals there is an increased risk of ... high competition for feed and water'. Thus research into the effects of stocking density and pasture allowance on dairy cow behaviour is timely.

The experimental design of the current study is similar to a previously published experiment (O'Driscoll et al., 2015), but with improved behaviour recording methodology. In addition to the effects of herbage allowance, the current study allowed the effect of time on treatment and carry-over effects to be investigated, while accounting for pre-experimental measurements. Thus the current study contributes new knowledge to that obtained from previous research. 


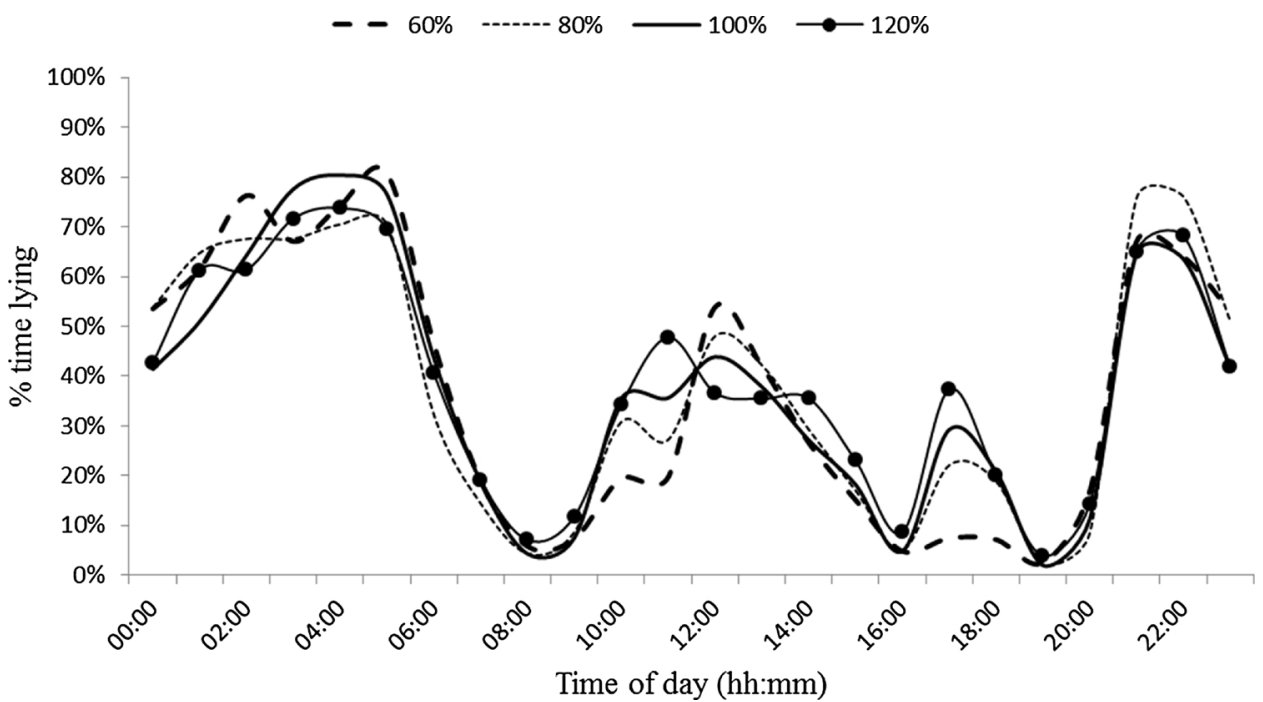

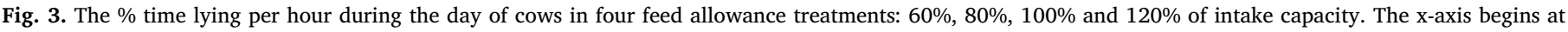
00:00, and each data point represents the proportion of time cows spent lying during the preceding hour.

The daily lying times we observed (approx. 9.5 h) are extremely similar to lying times reported by O'Driscoll et al. (2015; approx. $9.25 \mathrm{~h}$ ), and appear to be typical for cows at pasture in early to midlactation (approx. 9.8 h, Dalley et al., 1999; $8.3 \mathrm{~h}$, Tucker et al., 2007; $8.5 \mathrm{~h}$, Sepulveda-Varas et al., 2014). Nevertheless, in contrast to the previous work, in the current study we found that there was an effect of feed allowance on daily lying time, with lying times generally increasing with feed allowance. We also found that both overall and within treatment, daily lying times increased as the lactation progressed, which is in line with previous research (Ito et al., 2014). Although there was a similar pattern of increase over time in all treatments this was delayed in cows on the $60 \%$ treatment relative to the others; indeed after 6 weeks on treatment cows in the $60 \%$ treatment had lower lying times than those in the $120 \%$ treatment (due to numerically lower lying bout duration and number). This aligns with the pasture analysis, as at 6 weeks on treatment herbage disappearance was lower for cows on the $60 \%$ treatment than all others. Thus it appears there may be an association between herbage disappearance and overall daily lying times.

Long lying bouts are thought to be associated with increased cow comfort (Drissler et al., 2005), usually with respect to physical surroundings. However the underfoot conditions at pasture were similar for all treatments. An alternative hypothesis is that cows on the $120 \%$ treatment had longer lying bouts as they spent less time searching for feed during each grazing bout before reaching intake capacity. This was also likely the reason for the short latency to lie after milking. Indeed O'Driscoll et al. (2010a, 2010b) also reported shorter standing and grazing bouts at this time in cows on a high nutrition allowance. With decreasing stocking density, cows graze down to a lower surface height more slowly, which is associated with an increased intake rate (Ganche et al., 2014).

This result is slightly different to that from our previous study, when a low DHA resulted in a similar shift towards fewer lying bouts, but differed in that the bouts were longer. We had hypothesised that this resulted from a lower rate of postural change as feed allowance decreased; cows could have been less motivated to stand and search for grass once the available herbage was depleted. The discrepancy could be due to the differences in behaviour recording methods; the more targeted behavioural recording strategy and use of a pre-experimental covariate likely yielded more accurate treatment comparisons. Moreover, during the 'POST' treatment period the numerically longer lying bouts of the $120 \%$ cows could have contributed to the overall means being greater.
Our results regarding the latency to lie down after milking are almost exactly in line with those from O'Driscoll et al. (2015), with a clear trend for a shorter latency as herbage allowance increased. This was the case after even only 3 weeks on treatment, with the pattern even clearer after 6 weeks, particularly for afternoon milking. As reviewed by Chilibroste et al. (2007) a period of fasting increases the duration of the first grazing bout once fresh feed is provided. Cows allocated a lower herbage allowance likely fasted for longer before the allocation of fresh feed after milking. Once cows were all allocated $100 \%$ DHA at the end of the experimental period, this pattern in the main disappeared. Although there was yet a tendency for herbage allowance to have an effect on time to lie after morning milking during the post experimental phase, this was not the case for afternoon milking. One reason for this could be that there was a longer period of fasting before morning milking, and fresh pasture assignment, than there was in the afternoon. Thus observation of lying behaviour after morning milking may be a more sensitive measure of whether feed availability is, or has been limited, and warrants further investigation.

This result is reflected in the proportion of time cows spent lying during each hour, over the $24 \mathrm{~h}$ period. In general, cows on the lower herbage allowance treatments spent less time lying per hour between 10:00 and 12:00, and 17:00 and 19:00. Again, these data are in line with previous research into the effect of herbage allowance on the pattern of daily lying (O'Driscoll et al., 2010a, 2015), and again we hypothesise that this is driven by a longer grazing bout after milking; when overall herbage allowance is low cows are likely motivated to consume as much as they can due to a lower feeling of satiety, and prior to conspecifics consuming it (O'Driscoll et al., 2010b). Interestingly, in the current study the pattern when it came to proportion of time lying was completely reversed between the hour up to 11:00 and up to 12:00; up to 11:00 the higher the DHA, the more cows lying, whereas up to 12:00 the inverse was the case. This was driven mainly by a drop in the percentage cows lying in the $120 \%$ treatment, indicating that these cows may have already rested, and begun their second grazing bout post milking at this time.

Overall, these results indicate that differences in the daily pattern of lying, rather than total daily lying time, may be more useful when assessing the effects of nutrition level at pasture on animal behaviour. Observation of lying behaviour is often used as a tool to assess dairy cow welfare both in research, and in quality assurance schemes. One of the most significant findings from this study is that, in agreement with much of our previous experiments, we again found that a low herbage allowance is associated with increased standing times once cows are 
allocated fresh herbage. This could be taken into consideration when developing indicators for dairy cow welfare assessment in pasture based systems, or in other extensive systems. Further work should be carried out to determine whether the pattern of lying behaviour is affected more by internal factors such as the hunger-satiety axis, or external, such as stimuli from the pasture condition, in particular when environmental conditions are not comfort limiting (i.e. neither too hot, wet or cold).

\section{Conclusions}

Although the differences in lying behaviour that we observed do not imply impaired welfare per se, it is likely that changes to the pattern of lying behaviour resulted from a lack of satiety. However, the effects did not appear to be long lasting, as 7 weeks after the experiment finished behaviour had converged between treatments. There is potential for development of 'warning signals' for inadequate feed allocation, using herd level measurement of the percentage of cows standing at various times of the day. Further work should investigate how management factors such as milking time and fresh feed allocation could influence lying behaviour at herd level.

\section{References}

Charlton, G.L., Rutter, S.M., East, M., Sinclair, L.A., 2011. Effects of providing total mixed rations indoors and on pasture on the behavior of lactating dairy cattle and their preference to be indoors or on pasture. J. Dairy Sci. 94, 3875-3884.

Chen, W., Holden, N., 2018. Bridging environmental and financial cost of dairy production: a case study of Irish agricultural policy. Sci. Total Environ. 615, 597-607.

Chilibroste, P., Soca, P., Mattiauda, D.A., Bentancur, O., Robinson, P.H., 2007. Short term fasting as a tool to design effective grazing strategies for lactating dairy cattle: a review. Aust J. Exp. Agric. 47, 1075-1084.

Coffey, E.L., Delaby, L., Fleming, C., Pierce, K.M., Horan, B., 2018. Multi-year evaluation of stocking rate and animal genotype on milk production per hectare within intensive pasture-based production systems. J. Dairy Sci. 101, 2448-2462.

DAFM (Department of Agriculture, Food and the Marine), 2010. Food Harvest 2020 Department of Agriculture, Fisheries, and Food, Dublin, Ireland.

Dalley, D.E., Roche, J.R., Grainger, C., Moate, P.J., 1999. Dry matter intake, nutrient selection and milk production of dairy cows grazing rainfed perennial pastures at different herbage allowances in spring. Aust. J. Exp. Agric. 39, 923-931.

Drissler, M., Gaworski, M., Tucker, C.B., Weary, D.M., 2005. Freestall maintenance: effects on lying behavior of dairy cattle. J. Dairy Sci. 88, 2381-2387.

Edmonson, A.J., Lean, I.J., Weaver, L.D., Farver, T., Webster, G., 1989. A body condition scoring chart for Holstein dairy cows. J. Dairy Sci. 72, 68-78.

EFSA, 2009. Scientific report of EFSA prepared by the Animal Health and Animal Welfare Unit on the effects of farming systems on dairy cow welfare and disease. Annex EFSA J. 1143, 1-7.

Faverdin, P., Baratte, C., Delagarde, R., Peyraud, J.L., 2011. Grazein: a model of herbage intake and milk production for grazing dairy cows. 1. Prediction of intake capacity, voluntary intake and milk production during lactation. Grass Forage Sci. 66, 29-44.

Finneran, E., Crosson, P., Wallace, M., O'Kiely, P., Forristal, P.D., Shalloo, L., 2010. Simulation modelling of the cost of production and utilizing feeds for ruminants on Irish farms. J. Farm Manag. 14, 95-116.

Fisher, A.D., Verkerk, G.A., Morrow, C.J., Matthews, L.R., 2002. The effects of feed restriction and lying deprivation on pituitary-adrenal axis regulation in lactating cows. Livest. Prod. Sci. 73, 255-263.

Ganche, E., Delaby, L., O’Donovan, M., Boland, T.M., Galvin, N., Kennedy, E., 2013. Postgrazing sward height imposed during the first 10 weeks of lactation: influence on early and total lactation dairy cow production, and spring and annual sward characteristics. Livest. Sci. 157, 299-311.

Ganche, E., Delaby, L., O’Donovan, M., Boland, T.M., Kennedy, E., 2014. Short-term response in milk production, dry matter intake, and grazing behaviour of dairy cows to changes in postgrazing sward height. J. Dairy Sci. 97, 3028-3041.

Hurtado-Uria, C., Hennessy, D., Shalloo, L., O'Connor, D., Delaby, L., 2013. Relationships between meteorological data and grass growth over time in the south of Ireland. Ir. Geogr. 46.

Ito, K., Chapinal, N., Weary, D.M., von Keyserlingk, M.A.G., 2014. Associations between herd-level factors and lying behaviour of freestall-housed dairy cows. J. Dairy Sci. 97, 2081-2089.

Matthews, L.R., Cameron, C., Sheahan, A.J., Kolver, E.S., Roche, J.R., 2012. Associations among dairy cow body condition and welfare-associated behavioural traits. J. Dairy Sci. 95, 2595-2601.

Meikle, A., de Lourdes Adrien, M., Mattiauda, D.A., Chilibroste, P., 2014. Effect of sward condition on metabolic endocrinology during the early postpartum period in primiparous grazing dairy cows and its association with productive and reproductive performance. Anim. Feed Sci. Tech. 186, 139-147.

Munksgaard, L., Simonsen, H.B., 1996. Behavioral and pituitary adrenal-axis responses of dairy cows to social isolation and deprivation of lying down. J. Anim. Sci. 74, 769-778.

Munksgaard, L., Jensen, M.B., Pedersen, L.J., Hansen, S.W., Matthews, L., 2005. Quantifying behavioural priorities-effects of time constraints on behaviour of dairy cows, Bos taurus. Appl. Anim. Behav. Sci. 92, 3-14.

O'Driscoll, K., Boyle, L., Hanlon, A., 2008. A brief note on the validation of a system for recording lying behaviour in dairy cows. Appl. Anim. Behav. Sci. 111, 195-200.

O'Driscoll, K., O’Brien, B., Gleeson, D., Boyle, L., 2010a. Effect of milking frequency and nutritional level on hoof health, locomotion score and lying behaviour of dairy cows. Livest. Sci. 127, 248-256.

O’Driscoll, K., O’Brien, B., Gleeson, D., Boyle, L., 2010b. Milking frequency and nutritional level affect grazing behaviour of dairy cows: a case study. Appl. Anim. Behav. Sci. 122, 77-83.

O’Driscoll, K., Lewis, E., Kennedy, E., 2015. Effect of feed allowance at pasture on lying behaviour and locomotory ability of dairy cows. Appl. Anim. Behav. Sci. 166, 25-34.

Schütz, K.E., Cox, N.R., Macdonald, K.A., Roche, J.R., Verkerk, G.A., Rogers, A.R., Tucker, C.B., Matthews, L.R., Meier, S., Webster, J.R., 2013. Behavioral and physiological effects of a short-term feed restriction in lactating dairy cattle with different body condition scores at calving. J. Dairy Sci. 96, 4465-4476.

Sepulveda-Varas, P., Weary, D.M., von Keyserlingk, M.A.G., 2014. Lying behaviour and post-partum health status in grazing dairy cows. J. Dairy Sci. 97, 6334-6343.

Shepley, E., Bergeron, R., Vasseur, E., 2017. Daytime summer access to pasture vs. Free stall barn in dairy cows with year-long outdoor experience: a case study. Appl. Anim. Behav. Sci. 192, 10-14.

Tucker, C.B., Dalley, D.E., Burke, J.-L.K., Clarke, D.A., 2007. Milking cows once daily influences behavior and udder firmness at peak and mid lactation. J. Dairy Sci. 90, 1692-1703.

Vasseur, E., Rushen, J., Haley, D.B., de Passille, A.-M., 2012. Sampling cows to assess lying time for on-farm animal welfare assessment. J. Dairy Sci. 95, 4968-4977.

Wechsler, B., 1995. Coping and coping strategies: a behavioural view. Appl. Anim. Behav. Sci. 43, 123-134.

Wagner, K., Brinkmann, J., March, S., Hinterstoißer, P., Warnecke, S., Schüler, M., Paulsen, H.M., 2018. Impact of daily grazing time on dairy cow welfare-results of the welfare quality ${ }^{\oplus}$ protocol. Animals 8, 1-11.

Westin, R., Vaughan, A., de Passillé, A.M., DeVries, T.J., Pajor, E.A., Pellerin, D., Siegford, J.M., 2016. Lying times of lactating cows on dairy farms with automatic milking systems and the relation to lameness, leg lesions, and body condition score. J. Dairy Sci. 99, 551-561. 